\title{
BONE INGROWTH INTO MADREPORIC PROSTHESES
}

\author{
M. PORTIGLIATTI BARBOS
}

\author{
From the Institute of Clinical Orthopaedics and Traumatology, University of Torino
}

\begin{abstract}
Three madreporic prostheses in two patients were examined to evaluate resorption and formation of the surrounding bone tissue. All three prostheses were firmly fixed and had no clinical or radiographic signs of loosening. Transverse sections were examined by scanning electron microscopy at 40 days, 11 months and 2.5 years after implantation.

The findings suggest that adaptive bone remodelling varies along the length of the stem; that bone resorption and formation are related to the time after implant; and that new bone formation (woven bone) can be found very close to the madreporic surface.
\end{abstract}

Porous coating of orthopaedic implants, which aims to promote bone ingrowth after arthroplasty, offers a valuable alternative to fixation with acrylic cement. Animal experiments and clinical experience have substantiated the view that bone grows into the spaces of porous-coated implants (Welsh, Pilliar and Macnab 1971; Homsy et al. 1972; Kenesi, Touzet and Martraire 1976: Patel, Guillemin and Patat 1977; Rhinelander 1977; Bobyn et al. 1980; Bobyn and Engh 1985; Cook, Walsh and Haddad 1985). After implantation of madreporic surfaced prostheses, bone remodelling in dogs was evident (Lord et al. 1978; Lord, Hardy and Kummer 1979); histological studies and microradiographs revealed extensive mineralised bone growth (both haversian bone and woven bone) deep inside the spaces within the metallic surface. However, because of the difficulty of obtaining and processing specimens, histological studies of bone remodelling around a madreporic prosthesis in humans has been poorly documented. Using scanning electron microscopy (SEM) a study of three madreporic prostheses in humans was therefore performed. The major questions were: whether bone penetrates the madreporic surface and fixes the implant uniformly, and if not, which are the preferred sites of bone ingrowth; how long stabilisation of the implant by bone ingrowth takes; and what type of bone tissue will be found at the bone-metal interface.

\section{MATERIALS AND METHODS}

Both the right and left femora of a 70-year-old-man who had died of a heart attack were examined (Figs 1 to 5). $\mathrm{He}$ had had advanced bilateral arthritis and a Lord

M. Portigliatti Barbos, MD

Istituto di Clinica Ortopedica e Traumatologica, Università di Torino CTO, Via Zuretti 29, 10126 Torino, Italy.

(C) 1988 British Editorial Society of Bone and Joint Surgery

0301-620X/88/1022 $\$ 2.00$

J Bone Joint Surg [Br] 1988;70-B:85-8. (madreporique) prosthesis had been implanted in the left hip 11 months before he died; the right hip was treated in the same way 40 days before his death. A third Lord prosthesis, which had a rotational defect, was removed by longitudinal osteotomy of the diaphysis from a 62 year-old woman 2.5 years after surgery (Figs 6 to 9 ).

All three prostheses had been securely fixed, and there were no clinical or radiological signs of loosening. The specimens were radiographed with high-definition film and then transverse sections were cut at various distances from the hip (Fig. 1). Particular care was taken to avoid fractures or other artefacts at the bone-metal interface.

All the samples were fixed and dehydrated in graded ethyl alcohol solutions and embedded for study without decalcification. They were then placed directly into plastic blocks for simultaneous cross-sectioning of bone and metal to avoid any artifactual changes at the bonemetal interface. The transverse sections were then prepared for SEM under vacuum conditions. The polished surfaces were etched with $\mathrm{N} / 10 \mathrm{HCl}$ for one minute to enhance the detection of lamellar distribution (Boyde 1972) and finally coated with sputtering silver.

\section{RESULTS}

Case 1. 40 days after being implanted. The sections from the bone-metal specimen are shown in Figure 2 (the upper extremity of the implant) and Figure 3 (middle third). Most of the madreporic surface shows no ingrowth of bone; the upper sections show a wide zone at the lateral and posterior interface where bone trabeculae are completely absent (Fig. 2). The middle (Fig. 3) and lower parts of the stem are surrounded by cortical bone; there is macroscopic evidence of very extensive boneimplant contact, but no sign of new bone apposition. The SEM showed that there was no ingrowth at the boneimplant interface (Fig. 4); nor was there any evidence of significant bone resorption in the femur. 


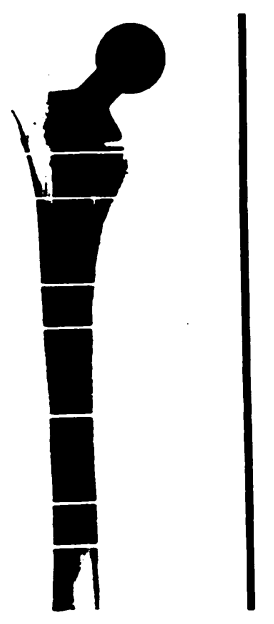

Fig. 1

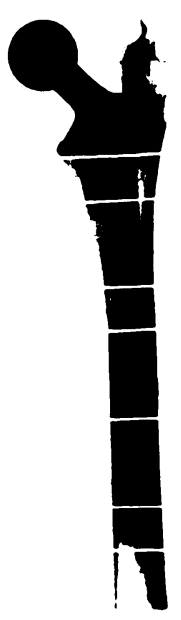

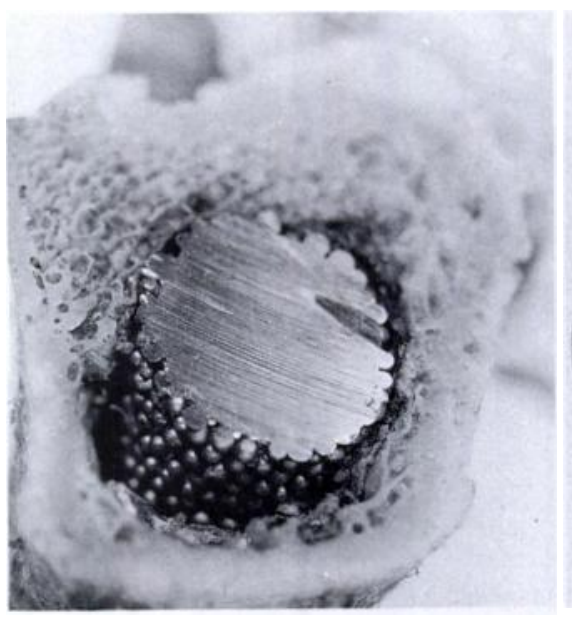

Fig. 2

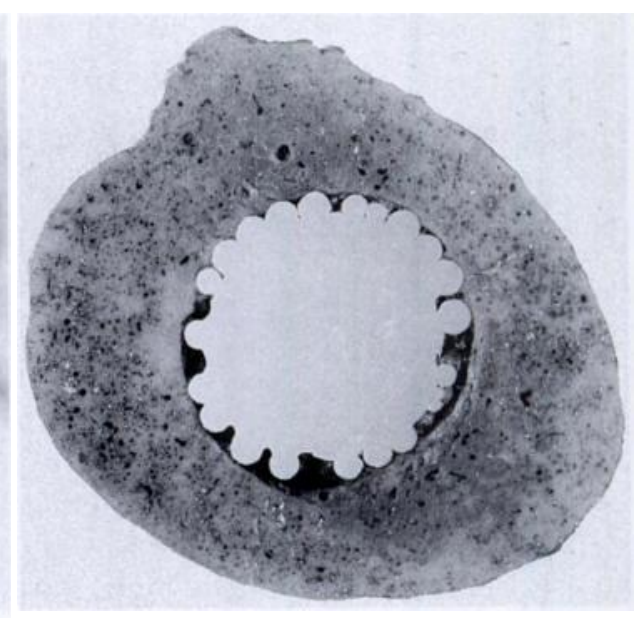

Fig. 3

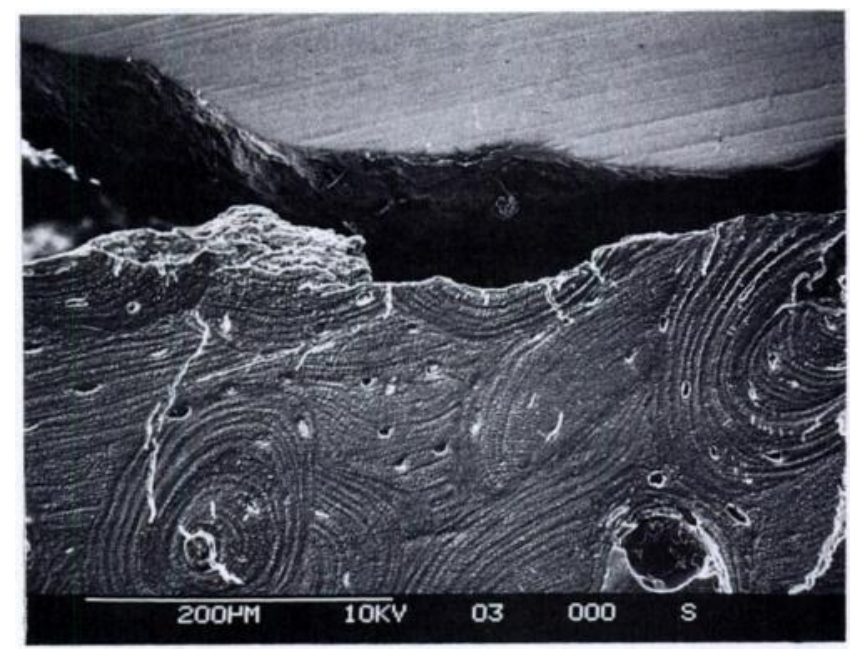

Fig. 4

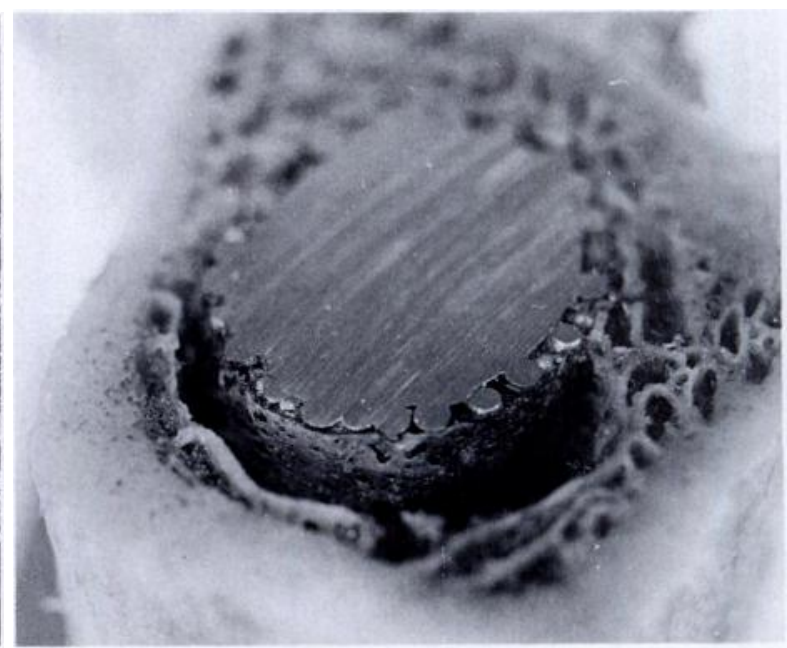

Fig. 5

Case 1. Figure 1 - The right and left femora of a 70-year-old man. The left prosthesis was implanted 11 months before the patient's death, and the right 40 days before. Figure $2-A$ transverse section of the right femur and prosthesis cut at the upper level of the femoral stem 40 days after being implanted: there is no bone formation at the surface. Figure $3-A$ section from the middle third shows extensive boneimplant contact. Figure 4 - The interface between bone (below) and implant (above) clearly shows the absence of bone ingrowth (SEM $x$ 150). Figure $5-A$ transverse section from the upper part of the left femoral stem 11 months after implant: the madreporic surface is covered by a thin layer of newly-formed bone.

11 months after being implanted. In Figure 5, bone apposition and growth on the madreporic surface of the femoral prosthesis is seen; this is particularly evident in a narrow zone of the posterior and lateral region of the upper part of the implant.

When compared with the section taken from a similar site at 40 days (Fig. 2), Figure 5 shows that the prosthesis has been covered by a thin layer of newly formed bone, usually without filling the spaces of the madreporic surface. Initial bone ingrowth is also evident in the lower part of the implant, and connective tissue can be seen where there is no bone ingrowth. Congruence between the prosthesis and the bone diaphysis is once again very poor at this site, especially when compared with the middle third of the femoral prosthesis. Finally, the old cortical bone seems to be more osteoporotic than that seen in the 40-day specimen.

Case 2. 2.5 years after being implanted. There is a thick layer of bone almost completely covering the lower third of the madreporic surface (Fig. 6). The middle and upper thirds are not covered by bone, but during the operation to remove the prosthesis, negative imprints of the balls of the madreporic surface were noted in the surrounding endosteal bone. This probably means that, despite good diffuse bone-metal contact, the mechanical strength of biological anchorage was greater in the lower part of the implant than in the upper third.

SEM showed extensive bone ingrowth at the bonemetal interface, often extending to the core of the madreporic surface (Fig. 7); however, in other areas, there was a gap between metal and bone (Fig. 8). Moreover, although bone tissue was observed in apparent contact with the implant surface in some areas, it was often separated by a thin membrane of fibrous tissue.

The new bone had the characteristics of woven bone, and was typically found at the interface and within 


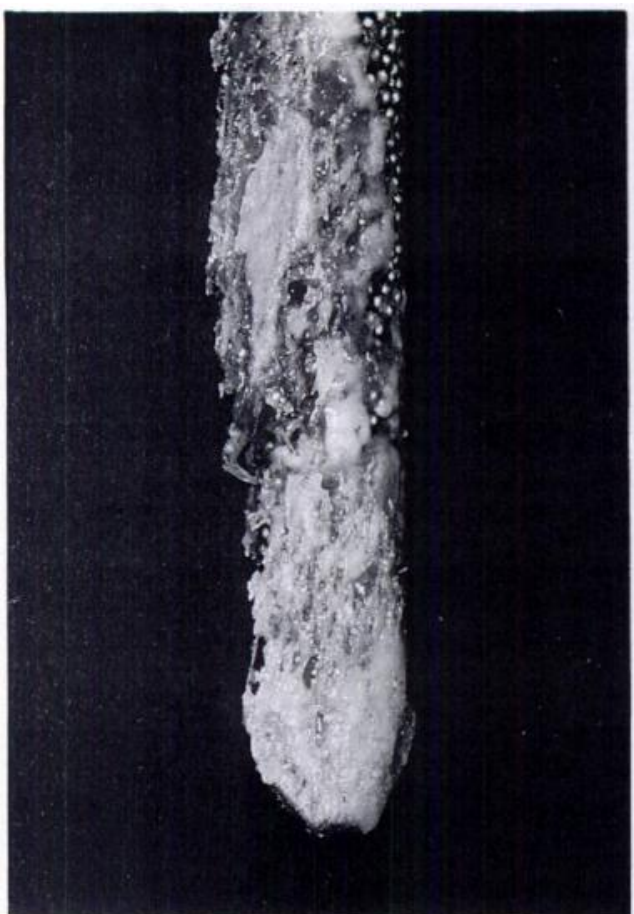

Fig. 6

Case 2. Figure 6 - The tip of a Lord (madreporique) stem removed from a 62-yearold woman after 2.5 years because of a rotational defect: note the endosteal bone ingrowth providing biological anchorage. Figure 7 - There is excelient bone ingrowth into the spaces on the implant surface $(S E M \times 150)$. Figure 8 - In some areas, there is new ingrowth within the pores of the madreporic surface, but there is still a gap between metal and bone $($ SEM $\times 75)$. Figure 9 - Newly-formed woven bone at the interface between lamellar cortical bone (above) and the prosthesis (below). The gap between the endosteal wall of the diaphysis and the madreporic surface is very narrow $($ SEM $\times 375)$.

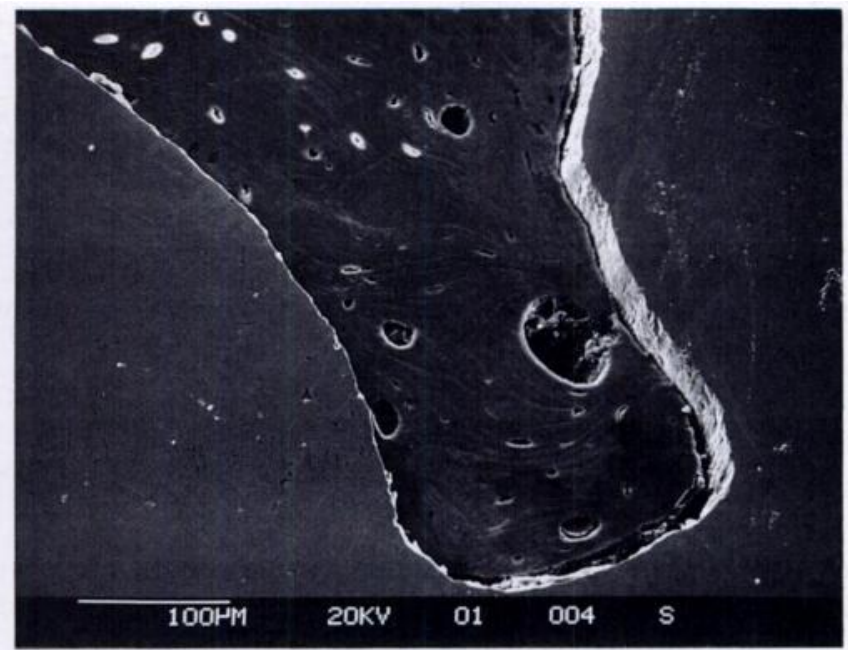

Fig. 7

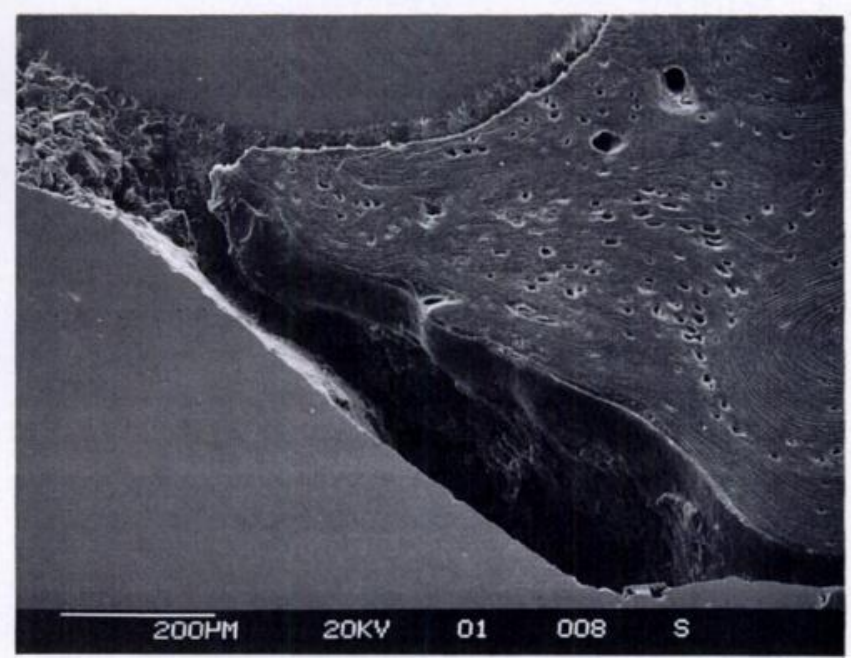

Fig. 8

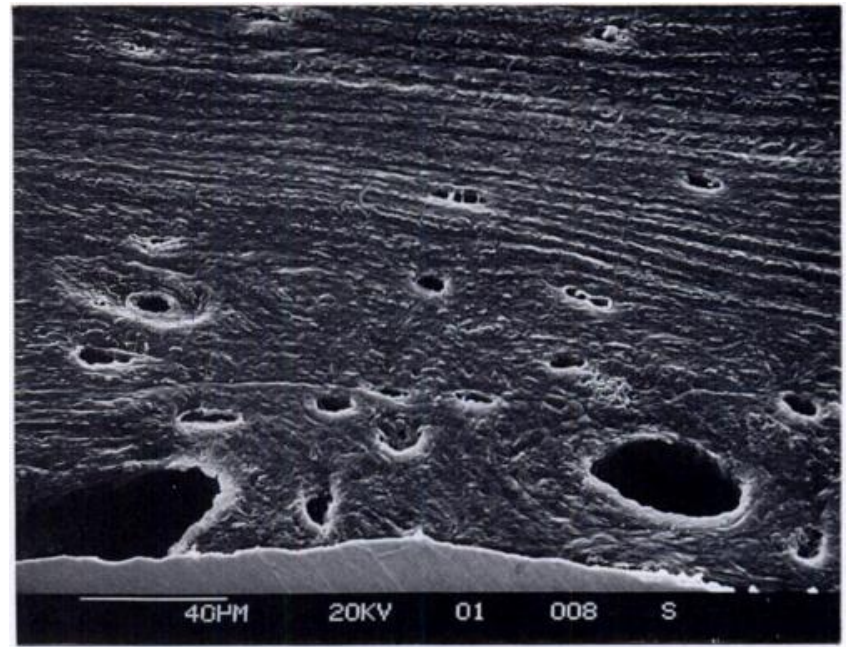

Fig. 9 
the madreporic spaces (Fig. 9). The morphological characteristics of this type of bone are very different from the lamellar structures of the haversian systems of diaphyseal bone. The osteocytic lacunae, too, are usually greater and wider than those of cortical bone. Some resorptive lacunae were also evident in the newly-formed bone (Fig. 9).

\section{DISCUSSION}

All three prostheses had a better bone-metal contact in the lower part of the implant, that is, in the cortical bone of the femur. In agreement with Lord et al. (1979), it thus seems that the closer the contact between the diaphysis and the implant, the greater the new bone formation in the madreporic spaces.

Obviously these morphological data are influenced by the anatomical features of the femur, by the size of the prosthesis in relation to that of the medullary canal, and by the effect of macro- and micromovement at the boneimplant interface.

No firm answer can be given about the time needed for bone ingrowth in man, but it is evident from this study that extensive bone formation is still under way at 11 months after implantation, and that the madreporic surface is diffusely infiltrated by osseous tissue after 2.5 years.

\section{REFERENCES}

Bobyn JD, Pilliar RM, Cameron HU, Weatherly GC. The optimum pore size for the fixation of porous-surfaced metal implants by the ingrowth of bone. Clin Orthop 1980;150:263-70.

Bobyn JD, Engh CA. Human histology of the biological fixation of porous coated hip prostheses. Transactions of the Fifth European Conference on Biomaterials, Paris, September 4-6, 1985:192.

Boyde A. Scanning electron microscope studies of bone. In: Bourne $\mathrm{GH}$, ed. The biochemistry and physiology of bone. New York etc: Academic Press, 1972:259-309.

Cook SD, Walsh KA, Haddad RJ Jr. Interface mechanics and bone growth into porous $\mathrm{Co}-\mathrm{Cr}-\mathrm{Mo}$ alloy implants. Clin Orthop 1985:193:271-80.

Homsy CA, Cain TE, Kessler FB, et al. Porous implant systems for prosthesis stabilization. Clin Orthop 1972;89:220-35.

Kenesi C, Touzet $\mathbf{P}$, Martraire $M$. Un nouveau type de stellite réhabitable; étude mécanique et histologique. Acta Orthop Belg 1976:Suppl 42:16-21.

Lord G, Marotte JH, Blanchard JP, Guillamon JL, Gory M. Étude expérimentale de l'ancrage des arthroplasties totales madréporiques de hanche. Rev Chir Orthop 1978;64:459-70.

Lord GA, Hardy JR, Kummer FJ. An uncemented total hip replacement : experimental study and review of 300 Madreporique arthroplasties. Clin Orthop 1979;141:2-16.

Patel A, Guillemin G, Patat JL. Résultats des testes mécaniques après implantation de métaux poreux ou à surface irréguliére. Rev Chir Orihop 1977:63 Suppl 2:116-9.

Rhinelander FW. A flexible composite as a coating for metallic implants: microvascular and histological studies. Int Orthop 1977:1:77-86.

Welsh RP, Pilliar RM, Macnab I. Surgical implants : the role of surface porosity in fixation to bone and acrylic. $J$ Bone Joint Surg [Am] $1971 ; 53-A$ :963-77. 